\title{
The Influence of Anabolic-Androgenic Steroids on Males' Hormones Among Gym-Goers in Mosul City
}

\author{
Abdulrahman Mazin Hashim ${ }^{1, *}$ Salwa Hazim Almukhtar ${ }^{2}$ \\ ${ }^{1}$ Clinical Nursing Department, Faculty of Nursing, Mosul University, Iraq \\ ${ }^{2}$ Clinical Nursing Department, Faculty of Nursing, Mosul University, Iraq \\ *Corresponding author. Email: aboodmazin1991@uomosul.edu.iq
}

\begin{abstract}
Anabolic-Androgenic Steroids (AAS) misuse are growing worldwide and misused especially among male bodybuilders and gyms-goers for building muscle to improve their physical appearance. AAS misuse is considered a preventable factor of male fertility because it affects the hypothalamic-pituitary-gonadal axis resulting in secondary male hypogonadism, and then transient or persistent suppression of spermatogenesis. Study aimed to investigate the influence of anabolic steroids misuse on the serum concentrations of follicle stimulating hormone, luteinizing hormone, and free testosterone. A prospective cohort study was conducted on 80 healthy male gym-goers divided into the case and control group who attending gyms in Mosul city. A structured interviewing questionnaire was used to collect information related to AAS misuse, blood sampling collected for evaluation of males' hormones in a private analytics Lab, for a period 25th October 2020 until 15th March 2021. Study finding shows that males' hormones of AAS group exhibited highly significant (P.>0.001) in the overall mean of serum concentrations of follicle stimulating hormone, luteinizing hormone, and free testosterone. ROC curve analysis reveals a highly significant deference at (P.>0.001) of males' hormones, which area under the curve was for follicle stimulating hormone: 0.94 , luteinizing hormone: 0.93 , and free testosterone: 0.81 . The misuse of AAS exhibited a severe decrease in concentrations of gonadotropins and free testosterone with may be considered an excellent predictor of secondary male hypogonadism. The study recommends the necessity to prevent abuse of anabolic steroids and instruct about the adverse effects that result from using it and especially on fertility.
\end{abstract}

Keywords: Anabolic-androgenic steroids, Males' hormones, Hypogonadism, Spermatogenesis.

\section{INTRODUCTION}

Anabolic steroids, or also known as androgenic steroids are manmade derivatives of testosterone and abbreviated as (AAS). Legal, as well as the illegal use of anabolic steroids, is gaining popularity [1].

AAS considered the most used agents worldwide to enhance performance, muscle growth, and body fat loss, as well as physical attractiveness. Anabolic-androgenic steroids are a synthetic steroid hormone that has anabolic and androgenic properties, and they are classified as steroids due to the inclusion of a steroid ring in their structure [2], [3].

Anabolic term indicates to hypertrophy of the body, while androgenic term indicates to enhance characteristics of the male sex that include muscle mass, deep voice, and facial hair. It has historically been used clinically to treat several medical cases, including delayed puberty, loss of muscle mass, AIDS, and cancer, but more recently, it has been used to encourage fat reduction and muscle building in a recreational sporting sense. Several studies have shown that these treatments have a wide range of side effects, including fertility and physiological complications, psychological problems, cardiovascular disease, and renal and hepatic disorders [4].

Testosterone is the most active endogenous androgen and is a 19-carbon steroid. Some athletes or gym-goers use AAS on a regular basis, while others want to minimize their possible side effects by using them in other ways, as Cycling (for periods of six to twelve weeks, users take AAS, followed by several weeks or even months off), Stacking (to increase the potency of the steroids, users mix many different steroid forms or add other supplements), Pyramiding (users steadily increase the dose until it reaches a peak, after which they reduce it), Plateauing (alternating, overlapping, or substituting with another steroid, where they alternate between periods with low and high doses to avoid developing a tolerance, also called "cruise and blast") [5], [6].

In the Middle East, a high prevalence of AAS abuse. In Lebanon was $10.7 \%$ [7]. In Saudi Arabia reports that 
using AAS 29.3\% and the use of AAS was more prevalent among gym members who practiced weightlifting (45.5\%) [8]. Furthermore, a survey of 200 gym users in Kuwait revealed a lifetime prevalence of (34\%) [9]. In Iraq, a nationally representative poll of 3200 people revealed that $(1.4 \%)$ of people had used AAS at some point in their lives [10].

"Taking testosterone is almost male contraception," says Dr. Brian Levine, managing partner and practice director of CCRM (The Colorado Center for Reproductive Medicine) New York. The MossmanPacey paradox, named after the two researchers who first identified it, refers to the use of testosterone or anabolic steroids to obtain muscle mass and thus look more pregnant while potentially raising one's chances of infertility [11].

Anabolic steroids promote muscle development quickly, but they can increase the risk of infertility and erectile dysfunction [12].

Mossman and Pacey point out in a recent issue of the Journal of Internal Medicine, while anabolic steroid abusers may appear superior at first glance, they are extremely likely to be unfit for reproductive purposes. This appears to be an evolutionary anomaly because we think reproduction is the underlying explanation for bodybuilding and gym-goers are aware of the side effects of anabolic steroids [13].

The normal spermatogenesis mechanism necessitates a combination of follicle-stimulating hormone and luteinizing hormone, which is compromised by AAS misuse, leading to infertility. Fortunately, research indicates that AAS-related infertility can be reversed, while sperm production can take up to a year to return to normal [14], [15].

Secondary male hypogonadism is a medical and societal concern that affects many people, the alteration in the follicle stimulating hormone, luteinizing hormone, and free testosterone, as well as changes in sperm concentration, motility, and/or morphology are responsible for about half of all cases of infertility in men. Recent advancements around infertility have had a significant impact on our perception of the various causes of male factor infertility. Though environmental, physiological, and genetic factors have been identified, misuse of anabolic-androgenic steroids (AASs) tends to affect sperm function and cause pregnancy delays [16].

There are some significant physiological effects of AAS on genital function, including development and growth of the penis, glands as seminal vesicles, and prostate, as well as effects on libido, orgasm, and arousal that regulated by the CNS, researches show the prolonged use for AAS supplementation with high-dosage, influence sexual function and it associated with higher rates of erectile dysfunction and decreased libido after cessation to use [17].

Exogenous testosterone and AAS inhibit the hypothalamic-pituitary system, which is not unexpected given that endogenous testosterone is the main regulator of the hypothalamic-pituitary-testicular axis. The resulting reduction in testosterone secreted and intratesticular testosterone, as well as spermatogenesis and sperm production, is caused by the deficiency of luteinizing hormone ( $\mathrm{LH})$ and follicle-stimulating hormone (FSH). Several experiments have shown that bodybuilders who use AAS have lower sperm concentrations and a greater incidence of azoospermia than controls. Clinical studies in male hormonal contraceptives are based on this impact [18].

\subsection{Specific Objectives of the Study:}

1. To evaluate the serum concentrations of follicle stimulating hormone, luteinizing hormone, and free testosterone of AAS abuser.

2. To predict for secondary male hypogonadism by finding the cut-off point of males' hormones among the study groups.

\section{METHOD AND MATERIALS}

Ethical approval was obtained to conduct the study from the University of Mosul/collegiate committee for medical research ethics (No.29, in 18/10/2020). The study's purpose and procedures were explained and emphasize the study participant's right to selfdetermination, confidentiality, and anonymity.

\subsection{Study Design:}

This study is a non-experimental, prospective cohort study with a nested case-control study to accomplish the objectives of the study for the period extended from $25^{\text {th }}$ October 2020 until $15^{\text {th }}$ March 2021.

\subsection{Study Setting:}

This study was conducted in Mosul city, capital of Nineveh Governorate, in northern Iraq, on (30) gymnasiums, (20) of it were distributed on the East side of the city and (10) were distributed on the West side of the city.

\subsection{Data Collection Period:}

The data of study has been collected in a period extending from $15^{\text {th }}$ of November 2020 to $20^{\text {th }}$ of February 2021.

\subsection{Sample of the Study:}

A non-probability sample was purposively selected according to the inclusion and exclusion criteria of gymgoers, invited from 30 gymnasiums, for the purpose of voluntarily participating in the study, a total number of 90 gym-goers were interviewed during the study period, and 10 of them were excluded due to did not match the study criteria.

\subsubsection{Inclusion Criteria:}

1. Male Healthy adults.

2. Age range (18-39) years. 
3. Gym-goers using anabolic steroids as a case group and those not using these steroids as a control group.

4. Current use for any type and duration of use for AAS.

5. Participants consent.

\subsubsection{Exclusion Criteria:}

1. Age less than (18 years) or more than (39 years).

2. Who suffering from diagnosed primary or secondary hypogonadism.

3. FSH and LH levels are elevated.

4. Refuse giving semen sample.

\subsection{Data Collection Method:}

The interview was conducted to fill out the questionnaire with the gym-goers in the laboratory, as well as blood sampling, each participant needed approximately (15-20) minutes to complete the data collection and blood sampling.

\subsubsection{Blood Sampling:}

A blood sample from each participant in the study was drawn from the antecubital vein after sterilization by venipuncture using a $3 \mathrm{ml}$ disposable syringe, the blood was placed in a standard laboratory tube, and the specimens are labeled with the participant's identification number and the collection date, this was done between 10:00 Am - 1:00 PM, for measurement of the concentrations of the follicle-stimulating hormone (FSH), luteinizing hormone (LH), and Free testosterone (Free T).

\subsection{Statistical Analysis:}

Statistical analysis of data was done by (SPSS) version 26, MedCalc Statistical Software for ROC curve analysis, as well as Microsoft Excel 365 for graphing. A descriptive approach was applied. Mean $\pm \mathrm{SD}$, median (range), or frequency (percentage) were computed. The parameters of gym-goers who use anabolic steroids and those who do not were compared using a Chi-square test. Mann-Whitney $U$ test for continuous variables that following non-normal distribution, the relative risk was calculated to determine the size of an effect.

\section{RESULTS}

Table 1 shows that the study participants were 80 bodybuilders, and there were no statistically significant differences in the demographic characteristics except the educational level between the AAS group and the control group, which refers to homogeneity between groups of the study.

Table 2 shows the overall mean of the participants for age was 25.95 , for height was 172.33 , for weight was 80.53 , and concerning body mass index (BMI), most of the participants were overweight with a mean of 27.04. Moreover, there were no statistically significant differences in the age, height, weight, and BMI between the AAS group and the control group, which refers to homogeneity between groups of the study.

Table 3 shows that $(60 \%)$ use two doselweek of AAS, for 1-6 months of duration (30\%), with Stacking pattern (72.5), some of them cessate using the AAS for about 1-2 months $(27.5 \%)$, and most of them don't use any accessory steroids $(80 \%)$.

Table 4 shown the overall mean of the AAS group for serum level of FSH was (1.28), LH was (1.79), and Free $\mathrm{T}$. was (11.93). On the other hand, the overall mean of the control group for serum level of FSH was (4.29), LH was (6.12), and Free T. was (23.18). Moreover, there were statistically significant differences between the AAS group and the control group of the study at $(\mathrm{P} .<0.01)$ in the hormonal assay.

Table 5 shows that AUC for FSH $=0.9391$ with significant differences $(\mathrm{P}=0.000)$, AUC for $\mathrm{LH}=0.9274$ with significant differences $(\mathrm{P}=0.000)$, and AUC for Free $\mathrm{T}$. $=0.8127$ with significant differences $(\mathrm{P}=0.000)$, as depicted in the figure (1).

Figure 2 Clarifies that short-duration use of AAS (less than one month) makes changes or effects less than longduration use (more than 18 months) on serum levels of gonadotropins (FSH and LH) as well as gonadal hormone (Free Testosterone) in the AAS group.

\section{DISCUSSION}

In this study, Table 1 shows that there are no significant differences between the AAS and control group concerning age, marital status, job status, and smoking status of the participants, it was $66 \%$ married, $37.5 \%$ students, and more than $60 \%$ was non-smoker, that indicate matching or homogeneity between the groups of the study and these variables does not affect the results of the study. However, the AAS group showed a significant difference at $(\mathrm{P} .<0.01)$ concerning the level of education $(\mathrm{P} .=0.001)$, in which $(45 \%)$ of AAS users have under diploma education level. In contrast, more than half of the control group have a diploma and above the educational level. This finding may refer to the AAS's awareness and its adverse consequences among the control group more than the AAS group. Similar data were obtained from another study conducted by [9].

The current study shows that the majority of the study participants were at ages between (19-28) years, and it represents $75 \%$ of the AAS group, and with age mean $(25.5 \pm 5.5)$, wiliest were smallest age group ranging between (34-38) years, this result can be explained as a difference between the age of interest to use the AAS, which those in the twenties age are usually more interested in their appearance of the body and performance, while those in the mid to late thirties usually don't have the same interests (Table 1). A study conducted by [19] agrees with our study when they found that most of the AAS users ages ranging from (15-24) years old, with an age mean $(25.4 \pm 6.1)$. 
Table 1. Characteristics of Case Study and Control Variables

\begin{tabular}{|c|c|c|c|c|c|}
\hline \multirow{2}{*}{$\begin{array}{l}\text { Variable } \\
\text { Age }\end{array}$} & \multicolumn{2}{|c|}{$\begin{array}{l}\text { AAS Group } \\
\qquad(n=40)\end{array}$} & \multicolumn{2}{|c|}{$\begin{array}{l}\text { Control Group } \\
\qquad(n=40)\end{array}$} & \multirow[t]{2}{*}{$\begin{array}{c}\text { Statistics } \\
\text { Chi-Sq. }(\chi 2) \text { tests }\end{array}$} \\
\hline & F. & $\%$ & F. & $\%$ & \\
\hline (19-23) years & 21 & 52.5 & 17 & 42.5 & \\
\hline (24-28) years & 9 & 22.5 & 11 & 27.5 & $\chi^{2}=1.530$ \\
\hline (29-33) years & 6 & 15 & 5 & 12.5 & \\
\hline (34-38) years & 4 & 10 & 7 & 17.5 & P-Value $=0.675$ \\
\hline Marital Status & F. & $\%$ & F. & $\%$ & $\chi^{2}=0.056$ \\
\hline Single & 13 & 32.5 & 14 & 35 & DF. $=1$ \\
\hline Married & 27 & 67.5 & 26 & 65 & P-Value $=0.500$ \\
\hline Job Status & F. & $\%$ & F. & $\%$ & \\
\hline Employed & 8 & 20 & 15 & 37.5 & $\chi^{2}=5.013$ \\
\hline Free-Job & 5 & 12.5 & 5 & 12.5 & DF. $=3$ \\
\hline Student & 15 & 37.5 & 15 & 37.5 & P-Value $=0.171$ \\
\hline Unemployed & 12 & 30 & 5 & 12.5 & \\
\hline Smoking Status & F. & $\%$ & F. & $\%$ & $\chi^{2}=0.853$ \\
\hline Not Smoker & 27 & 67.5 & 23 & 57.5 & DF. $=1$ \\
\hline Smoker & 13 & 32.5 & 17 & 42.5 & P-Value $=0.356$ \\
\hline Level of Education & F. & $\%$ & F. & $\%$ & \\
\hline Primary School & 13 & 32.5 & 7 & 17.5 & $\chi^{2}=18.373$ \\
\hline Secondary School & 18 & 45 & 8 & 20 & DF. $=4$ \\
\hline Institute & 9 & 22.5 & 13 & 32.5 & P-Value $=0.001 * *$ \\
\hline College & 0 & 0 & 9 & 22.5 & \\
\hline Postgraduate & 0 & 0 & 3 & 7.5 & \\
\hline Total & 40 & 100 & 40 & 100 & \\
\hline
\end{tabular}

Note: $* *=$ Significance at $P .<0.01$, N.: Number of Participants; F: Frequency; \%: Percent $; X^{2}:$ Chi-Sq.; DF: Degree of Freedom.

Table 2 shows the participant's height means was $(172.33 \pm 8.03) \mathrm{cm}$, weight mean was $(80.53 \pm 11.61) \mathrm{kg}$, and concerning body mass index (BMI) most of the participants were overweight with a mean of $(27.04 \pm 3.03)$ $\mathrm{kg} / \mathrm{m} 2$. And there were no statistically significant differences in the age, height, weight, and BMI between the AAS and control group, which refers to homogeneity between groups of the study. These variables were measured to exclude the effect of overweight on the hormonal concentrations of the (FSH, LH, Free T.), in addition to the quality of semen; a study conducted by[5], an observed mean of the BMI was(29.9 \pm 3.33$)$, and this concordant with our study finding.
We noted in our study some methods of misuse of anabolic steroids that included in table 4,

Forty percent of AAS group used the AAS for duration more than one and a half year, this can be explained by 
Table 2. Descriptive Statistics and Z-value of Mann-Whitney U test for the age, height, weight, and body mass index (BMI) for both AAS group and control groups

\begin{tabular}{lcccccc}
\hline Variables & \multicolumn{2}{c}{ AAS Group $(\mathbf{n = 4 0})$} & \multicolumn{2}{c}{ Control $(\mathbf{n = 4 0})$} & $\boldsymbol{Z}$ & $\boldsymbol{P}$-value \\
& $\overline{\mathbf{x}}$ & SD & $\overline{\mathbf{x}}$ & $\mathbf{S D}$ & & \\
\hline Age (years) & 25.55 & 5.462 & 26.35 & 5.93 & 0.58 & 0.559 \\
Height (cm) & 172.40 & 8.09 & 172.27 & 7.98 & 0.05 & 0.988 \\
Weight (kg) & 80.57 & 11.80 & 80.50 & 11.42 & 0.02 & 0.981 \\
Body Mass Index & 27.02 & 3.02 & 27.07 & 3.03 & 0.09 & 0.927 \\
\hline
\end{tabular}

Note: $\bar{x}:$ Mean; SD: Standard Deviation

Table 3. The frequency distribution of AAS misused by the AAS group

\begin{tabular}{|c|c|c|}
\hline Durations of Used AAS & F. & $\%$ \\
\hline Less than 1 month & 2 & $\overline{5}$ \\
\hline $1-6$ months & 12 & 30 \\
\hline $7-12$ months & 8 & 20 \\
\hline 13-18 months & 2 & 5 \\
\hline More than 18 months & 16 & 40 \\
\hline Patterns of Used AAS & F. & $\%$ \\
\hline Cycling & 10 & 25 \\
\hline Stacking & 29 & 72.5 \\
\hline Pyramidic & 0 & 0 \\
\hline Plateau & 1 & 2.5 \\
\hline Withdrawal Periods of AAS Used & F. & $\%$ \\
\hline $1-2$ months & 11 & 27.5 \\
\hline 3-4 months & 7 & 17.5 \\
\hline 5-6 months & 5 & 12.5 \\
\hline $7-8$ months & 8 & 20 \\
\hline More than 8 months & 4 & 10 \\
\hline Not withdrawal & 5 & 12.5 \\
\hline Total & 40 & 100 \\
\hline
\end{tabular}

Note: F.: Frequency; \%: Percentage.

the fact that AAS users become addicted to it, and for fear of losing muscle shape. More than seventy-two used Stacking pattern (means taking two or more different types of anabolic steroids), and (25\%) used Cycling pattern (means taking several doses of the same AAS over a set amount of time, pausing for a while, and then restarting), this can explain as abusers may think that they are reducing the risks caused by steroids when using a Stacking pattern. More than twenty-seven AAS users stopped using for a period of about (1-6 months); this may be the rest periods between one dose and another, a survey for characteristics and attitudes of males AAS users conducted by [20] agree with our study results. 
Table 4. Descriptive Statistics and Z-value of Mann-Whitney U test for the serum level of Follicle Stimulating Hormone, Luteinizing Hormone, and Free Testosterone for both AAS group and control groups

\begin{tabular}{|c|c|c|c|c|c|c|}
\hline \multirow{2}{*}{$\begin{array}{l}\text { Variables } \\
\text { Hormonal Assay }\end{array}$} & \multicolumn{2}{|c|}{$\begin{array}{l}\text { AAS Group } \\
\qquad(n=40)\end{array}$} & \multicolumn{2}{|c|}{$\begin{array}{l}\text { Control Group } \\
\qquad(n=40)\end{array}$} & \multicolumn{2}{|c|}{ Statistics } \\
\hline & $\overline{\mathbf{x}}$ & SD & $\overline{\mathbf{x}}$ & SD & $Z$ & $P$-value \\
\hline FSH (mIU/ml) & 1.28 & 1.78 & 4.29 & 1.77 & 6.11 & $0.000 * *$ \\
\hline LH (mIU/ml) & 1.79 & 2.32 & 6.12 & 2.51 & 5.99 & $0.000 * *$ \\
\hline Free T. $(\mathrm{pg} / \mathrm{ml})$ & 11.93 & 14.02 & 23.18 & 7.30 & 5.25 & $0.000 * *$ \\
\hline
\end{tabular}

Note: $* *=$ Significance at $P .<0.01, \bar{x}:$ Mean; SD: Standard Deviation; $m I U / m l:$ milli-international units per milliliter; $p g / m l$ : Picograms per milliliter.

Table 5. Receiver Operating Characteristic (ROC) Analysis of Follicle Stimulating Hormone, Luteinizing Hormone, and Free Testosterone

\begin{tabular}{lccccccc}
\hline \multirow{2}{*}{$\begin{array}{l}\text { Criterion } \\
\text { Variable }\end{array}$} & AUC & \multicolumn{2}{c}{$\mathbf{9 5 \%}$ CI } & Sensitivity & Specificity & Criterion & P.Value \\
\cline { 3 - 6 } & & Lower & Upper & & 88.9 & $\leq 1.1$ & $0.0000^{* *}$ \\
\hline FSH & 0.9391 & 0.8621 & 0.9737 & 96.2 & 88.89 & $\leq 1.5$ & $0.0000^{* *}$ \\
LH & 0.9274 & 0.8416 & 0.9675 & 96.15 & 87.4 & $\leq 12$ & $0.0000^{* *}$ \\
Free T. & 0.8127 & 0.6363 & 0.9083 & 88.46 & 876 \\
\hline
\end{tabular}

Note: $* *=$ Significance at $P .<0.01$, AUC: Area Under the Curve, CI: Confidence interval

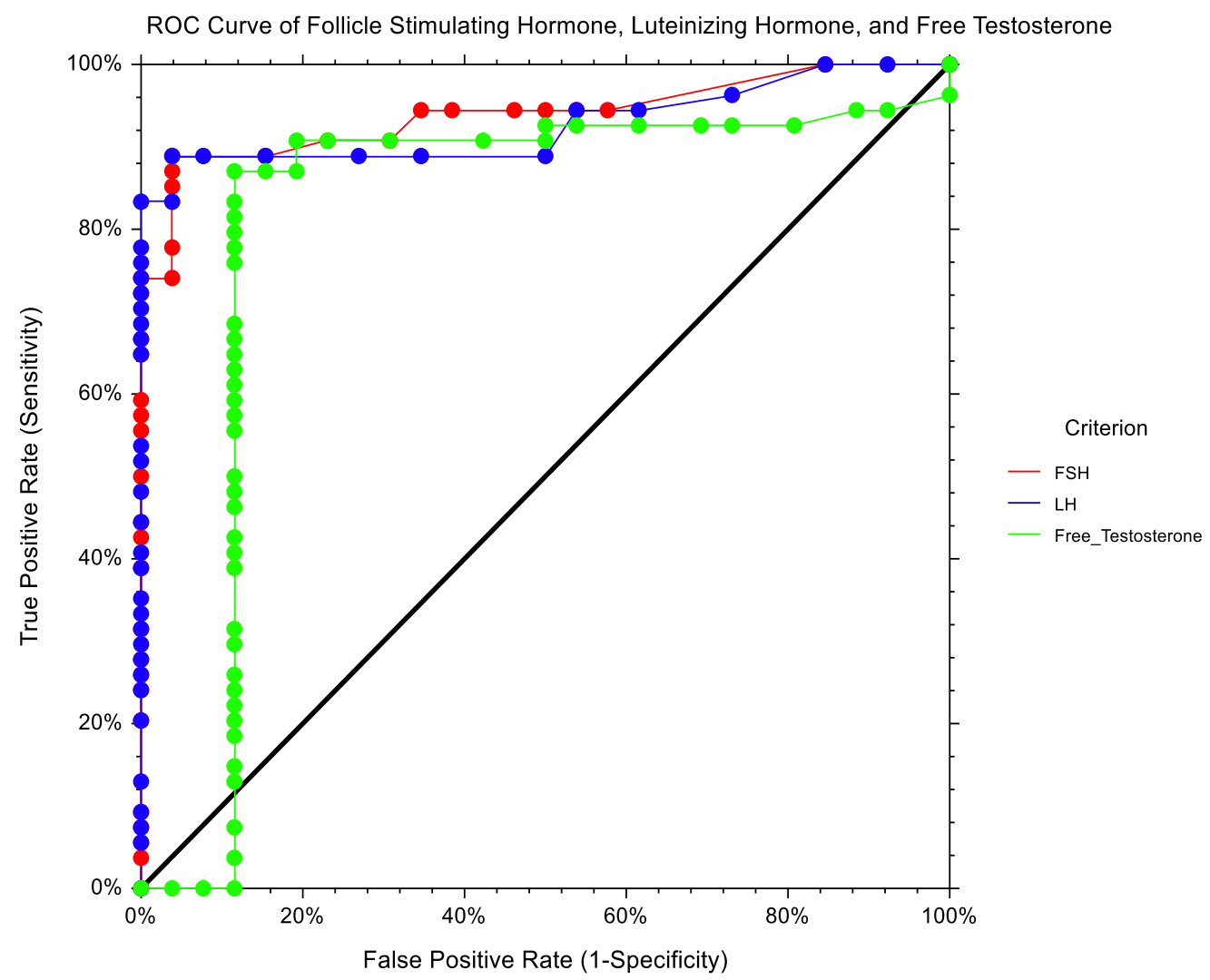

Figure 1 ROC Analysis of FSH, LH, and Free T.

Table 4, showed a significant decrease in serum levels of FSH (1.8 \pm 1.78$) \mathrm{mlU} / \mathrm{ml}, \mathrm{LH}(1.79 \pm 2.32) \mathrm{mlU} / \mathrm{ml}$, and
Free T. $(11.93 \pm 14.02) \mathrm{Pg} / \mathrm{ml}$ for the AAS group, in comparing the control group was FSH $(4.29 \pm 1.77)$ 


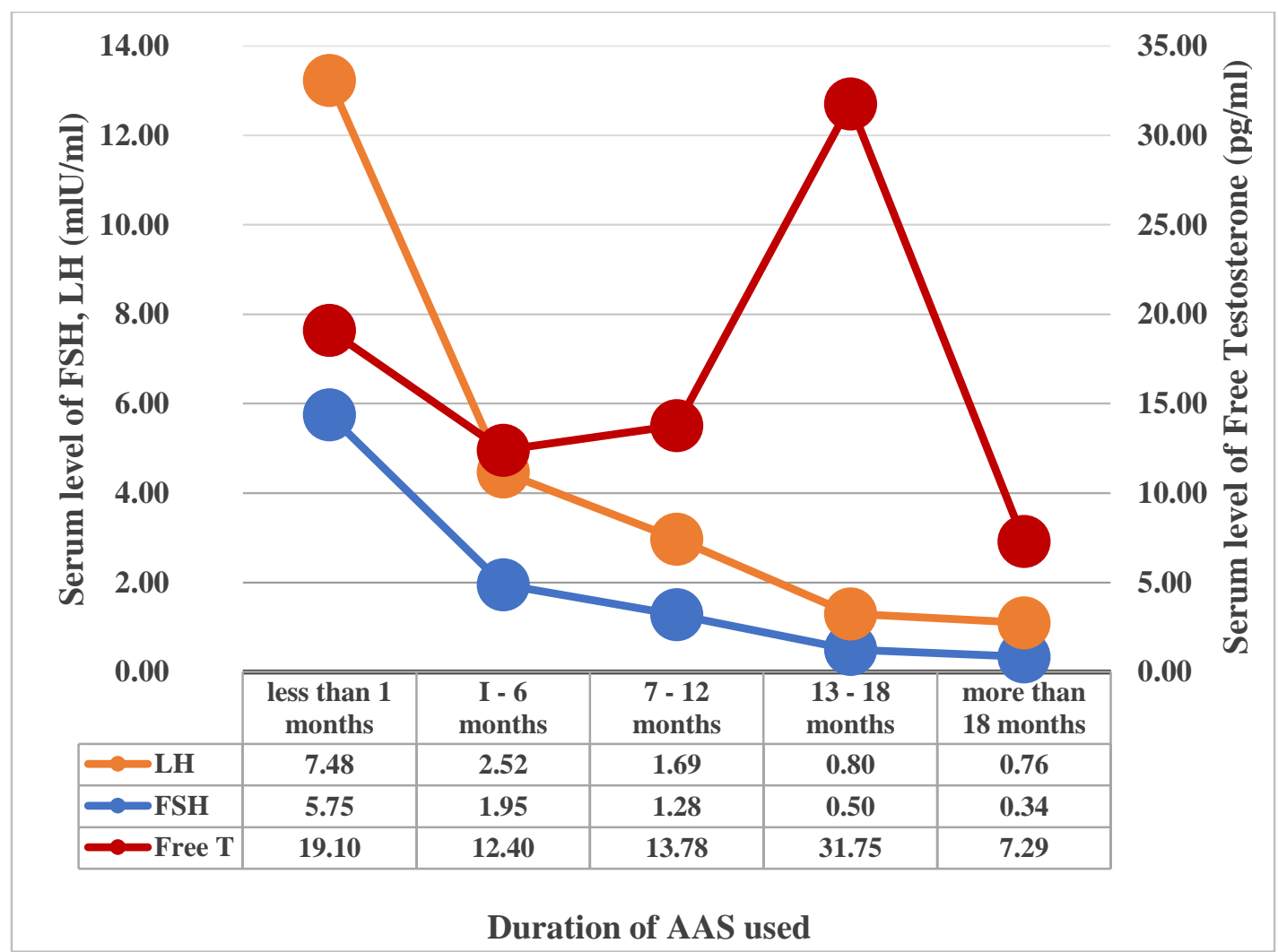

Figure 2 The relationship between duration of AAS used and its effect on the serum level of FSH, LH, and Free T. for the AAS group

$\mathrm{mlU} / \mathrm{ml}$, LH $(6.12 \pm 2.52) \mathrm{mlU} / \mathrm{ml}$, and Free $\mathrm{T}$. (23.18 \pm 7.30) Pg/ml. Mann-Whitney U test showed a high significance that was $(\mathrm{P}$-value $=0.000)$ between the groups at the level of (P.<0.01). These findings agree with the results of [21], [22] those who concluded that the random effect model suggested a significant decrease in total testosterone level following AAS cessation and in both LH and FSH concentrations amid the time of AAS use in athletes users, these findings can explain as anabolic steroids may suppress the hypothalamicpituitary-gonadal axis.

Table 5 and Figure 1, depicts the ROC curve for FSH, $\mathrm{LH}$, and free testosterone, the overall, FSH had the best response in terms of AUC (with a 95\% CI for the area being between 0.8621 and 0.9737 ), followed by $\mathrm{LH}$ (with a $95 \% \mathrm{CI}$ for the area being between 0.8416 and 0.9675 ), and free testosterone (with a $95 \%$ CI for the area being between 0.6363 and 0.9083 ), a cut-off value of $\leq 1.1 \mathrm{mIU} / \mathrm{mL}$ of FSH was significantly associated with a sensitivity of $96.2 \%$ and specificity of $88.9 \%$, a cut-off value of $\leq 1.5 \mathrm{mIU} / \mathrm{mL}$ of $\mathrm{LH}$ was significantly associated with a sensitivity of $96.15 \%$ and specificity of $88.89 \%$, and a cut-off value of $\leq 12 \mathrm{Pg} / \mathrm{mL}$ of free testosterone was significantly associated with a sensitivity of $88.46 \%$ and specificity of $87.04 \%$, with the occurrence of oligospermia to azoospermia in the AAS users of bodybuilders. A similar to the investigation by [23], which approximately agree with the present study finding, so based on ROC analysis for $\mathrm{FSH}, \mathrm{LH}$, and free testosterone, served as the best clinical indicators to discriminate the fertility status between AAS users and non-users.

Figure 2, represents that a shorter duration of anabolic steroids use has less effect than the long duration of use on the serum concentrations of the FSH, LH, and Tree T., which showed that less than one month of using anabolic steroids is an almost non-existent effect, but if used for one to six months have changes or effects less than the effect of use for more than one and a half year, the study conducted by [24] agrees with our finding related to serum levels of hormones.

These findings can explain that prolonged use of anabolic steroids may lead to temporary suppression of the hypothalamic-pituitary-gonadal axis result in the highly decreased production of body hormones and a substantial dependence on exogenous hormones included in the injectable AAS.

\section{CONCLUSIONS}

According to the objectives of the current study, discussion of results, and their interpretations, it can be concluded that a significant decrease in serum levels of FSH, LH, and Free T. of the AAS group compared to the control group, which was within normal limits. Using AAS for more than seven months associated suppression of serum levels of FSH, LH, and Tree T.

\section{RECOMMENDATIONS}

Depending on the findings and conclusions of the study, the researcher recommended the Iraqi Ministry of Health must activate the monitoring role over the abuse of 
AAS in gyms among bodybuilders and even nonprofessional athletes. Iraq Pharmacists Association must prevent pharmacies from selling anabolic steroids without a physician's prescription because it has been taken for non-medical or illegal use. Community health education through health promotion programs for gyms-goers about the long-term adverse effects that consequence using AAS.

\section{AUTHORS' CONTRIBUTIONS}

All authors contributed to the design, Hashim, A. M. implement the study, and verified the analytical methods, Almukhtar, S. H. supervised the findings of this work. All authors discussed the results and contributed to the final manuscript.

\section{ACKNOWLEDGMENTS}

I would like to express my deepest thanks and gratitude to the Deanship of the College of Nursing at the University of Mosul as well as to the Branch of Clinical Nursing Sciences for their assistance and facilitation of research requirements.

\section{REFERENCES}

[1] S. Odoardi, S. Mestria, G. Biosa, V. Valentini, S. Federici, and S. Strano Rossi, "An overview on performance and image enhancing drugs (PIEDs) confiscated in Italy in the period 2017-2019," Clin. Toxicol., vol. 59, no. 1, pp. 47-52, 2021, doi: $10.1080 / 15563650.2020 .1770277$

[2] S. Althobiti, N. Alqurashi, A. Alotaibi, T. Alharthi, and K. Alswat, "Prevalence, Attitude, Knowledge, and Practice of Anabolic Androgenic Steroid (AAS) Use Among Gym Participants," Mater. Socio Medica, vol. 30, no. 1, p. 49, 2018, doi: 10.5455/msm.2018.30.49-52.

[3] O. Harvey, S. Keen, M. Parrish, and E. van Teijlingen, "Support for people who use Anabolic Androgenic Steroids: A Systematic Scoping Review into what they want and what they access," BMC Public Health, vol. 19, no. 1, p. 1024, Jul. 2019, doi: 10.1186/s12889-019-7288-x.

[4] J. C. Perry, T. M. Schuetz, M. D. Memon, S. Faiz, and I. Cancarevic, "Anabolic Steroids and Cardiovascular Outcomes: The Controversy," Cureus, vol. 12, no. 7, 2020, doi: 10.7759/cureus.9333.

[5] L. E. Hauger, L. T. Westlye, and A. Bjørnebekk, "Anabolic androgenic steroid dependence is associated with executive dysfunction," Drug Alcohol Depend., vol. 208, no. October 2019, p. 107874, 2020, doi: 10.1016/j.drugalcdep.2020.107874.

[6] A. Conchin, F. Delvaux, R. P. Radermecker, A.
Neuprez, J. L. Croisier, and J. F. Kaux, "High intensive sports, what impacts on the musculoskeletal and endocrine system.," $J$. Traumatol. du Sport, vol. 37, no. 3, pp. 154-161, 2020, doi: 10.1016/j.jts.2020.06.001.

[7] A. J. Mufarrij, "The Prevalence and Determinants of Anabolic Steroids Use among Fitness Center Attendees in Lebanon Running Title: Anabolic Steroid Use among Gym ...," Researchgate.Net, pp. 1-21, 2020, [Online]. Available: https://www.researchgate.net/profile/Afif_Mufarrij /publication/289179855_The_prevalence_and_dete rminants_of_anabolic_steroid_use_among_fitness _centre_attendees_in_Lebanon/links/5bdb03ca928 51c6b279e4add/The-prevalence-and-determinantsof-anabolic-steroid-u.

[8] F. F. Al-Harbi, I. Gamaleddin, E. G. Alsubaie, and K. M. Al-Surimi, "Prevalence and risk factors associated with anabolic-androgenic steroid use: A cross-sectional study among gym users in Riyadh, Saudi Arabia," Oman Medical Journal, vol. 35, no. 2. 2020, doi: 10.5001/omj.2020.28.

[9] N. Khullar, N. Scull, M. Deeny, and E. Hamdan, "Prevalence and Predictors of AnabolicAndrogenic Steroid Use among Gym Users in Kuwait: A Preliminary Study," Int. J. Mens. Health, vol. 15, no. 2, p. 144, 2016, doi: $10.3149 /$ jmh.1502.144

[10] N. Al-Hemiery et al., "Self-reported substance use in Iraq: findings from the Iraqi National Household Survey of Alcohol and Drug Use, 2014," Addiction, vol. 112, no. 8, pp. 1470-1479, Aug. 2017, doi: 10.1111/add.13800.

[11] H. Horwitz, K. P. Dalhoff, and J. T. Andersen, "The Mossman-Pacey Paradox," J. Intern. Med., vol. 286, no. 2, pp. 233-234, 2019, doi: $10.1111 /$ joim. 12885 .

[12] H. Horwitz, J. T. Andersen, and K. P. Dalhoff, "Health consequences of androgenic anabolic steroid use," J. Intern. Med., vol. 285, no. 3, pp. 333-340, 2019, doi: 10.1111/joim.12850.

[13] W. de Ronde, "Preventing anabolic steroid abuse: A long way to go," Journal of Internal Medicine, vol. 285, no. 3. Blackwell Publishing Ltd, pp. 349-350, Mar. 01, 2019, doi: 10.1111/joim.12858.

[14] W. de Ronde and D. L. Smit, "Anabolic androgenic steroid abuse in young males," Endocr. Connect. vol. 9, no. 4, pp. R102-R111, 2020, doi: 10.1530/EC-19-0557.

[15] L. A. Esparza, T. Terasaka, M. A. Lawson, and A. S. Kauffman, "Androgen Suppresses In Vivo and In Vitro LH Pulse Secretion and Neural Kiss1 and Tac2 Gene Expression in Female Mice," 
Endocrinology, vol. 161, no. 12, Dec. 2020, doi: 10.1210/endocr/bqaa191.

[16] R. Dcunha et al., "Current Insights and Latest Updates in Sperm Motility and Associated Applications in Assisted Reproduction," Reproductive Sciences. Springer Science and Business Media Deutschland GmbH, 2020, doi: 10.1007/s43032-020-00408-y.

[17] J. M. Armstrong et al., "Impact of anabolic androgenic steroids on sexual function," Transl. Androl. Urol., vol. 7, no. 3, pp. 483-489, 2018, doi: 10.21037/tau.2018.04.23.

[18] J. A. McBride and R. M. Coward, "Recovery of spermatogenesis following testosterone replacement therapy or anabolic-androgenic steroid use," Asian Journal of Andrology, vol. 18, no. 3. Medknow Publications, pp. 373-380, May 01, 2016, doi: 10.4103/1008-682X.173938.

[19] R. K. Lafta and G. A. Mohammad, "Anabolic Supplements Abuse among Athletes in Baghdad Gyms," IRAQI JOURNALOF COMMUNITY Med., vol. 25 , no. $4,2012$.

[20] A. K. Bonnecaze, T. O’Connor, and J. A. Aloi, "Characteristics and Attitudes of Men Using Anabolic Androgenic Steroids (AAS): A Survey of 2385 Men," Am. J. Mens. Health, vol. 14, no. 6, p. 1557988320966536, 2020.

[21] F. S. Abdulhadi, A. A. Zabbon, and S. A. H. A. Rahman, "Effect of nutritional supplementation and anabolic androgen with testosterone on kidney and liver function of athletes in Baghdad City," J. Glob. Pharma Technol., vol. 10, no. 7, pp. 231-235, 2018.

[22] M. A. Christou, P. A. Christou, G. Markozannes, A. Tsatsoulis, G. Mastorakos, and S. Tigas, "Effects of Anabolic Androgenic Steroids on the Reproductive System of Athletes and Recreational Users: A Systematic Review and Meta-Analysis," Sport. Med., vol. 47, no. 9, pp. 1869-1883, 2017, doi: 10.1007/s40279-017-0709-z.

[23] I. S. Huang, W. J. Huang, and A. T. Lin, "Distinguishing non-obstructive azoospermia from obstructive azoospermia in Taiwanese patients by hormone profile and testis size," J. Chinese Med. Assoc., vol. 81, no. 6, pp. 531-535, 2018, doi: 10.1016/j.jcma.2017.09.009.

[24] J. J. Rasmussen et al., "Former abusers of anabolic androgenic steroids exhibit decreased testosterone levels and hypogonadal symptoms years after cessation: A case-control study," PLoS One, vol. 11, no. 8, pp. 1-16, 2016, doi: 10.1371/journal.pone.0161208. 